\title{
Homenaje Checoslovaco a Miguel Angel Asturias
}

- Me enamoré de Praga y de los praguenses-, declaró Miguel Angel Asturias durante su encuentro con los escritores checoslovacos, y así se titula el primer artículo informativo sobre su vida, obra y planes literarios salido de la pluma de uno de los participantes de esa velada, el eminente hispanista checo Zdenek Hampl, quien además intentó captar en él la atmósfera vibrante de la primera visita del creador del fabuloso mundo de los mayas en calidad de embajador de si mismo - $\mathrm{y}$ del cosmos que constituye- a mi patria (en el semanario Kultura, 1957, № 39 , p. 2). Se sembró la amistad en tierra fértil y no pudo sino germinar. Ese punto de partida equivale al año 1957 . Siembra de otoño que espera la vuelta del sol.

La primera "golondrina" apareció en la revista Svetová literatura ( $\mathrm{Li}$ teratura mundial, 1960, № 4, pp. 44-79): dos cuentos iniciales de Weekend en Guatemala en la traducción de Zdenek Hampl, quien los introdujo con una acertada caracterización de la vida y obra del autor. $Y$ pronto empezaron a echar tallos otras semillas. Bajo el nombre de uno de los poemas, "Autoquiromancia", vio la luz una pequeña antología de versos compilada, en el fondo, de Sien de Alondra, por Vlastimil Maršičck y Alena Novohradská (ed. Mladá fronta, Praga, 1961). Pese a sus defectos, en el proceso de acercamiento a la obra de Asturias, esta antología cumplió con su deber. Los traductores subestimaron, en particular, el valor poético de la palabra en su poesía. Permítaseme referirme brevemente al respecto y señalar uno de sus aspectos, lo que constituirá un homenaje checoslovaco sui generis al poeta guatemalteco. Como punto de partida, me serviré de las declaraciones del propio Asturias:

(...) estoy acostumbrado a pesar cada palabra. El escribir es para mí, a la vez, una cuestión también un poco auditiva: Las páginas 
escritas las leo siempre en voz alta y cuando me gusta la oración, es decir cuando me "suena", la dejo sin cambiarla; si no me parece la cambio. (Entrevista en Literaini listy, 1968, No 15, p. 11.)

Por lo tanto, no sorprende que el verso de Asturias sea sensiblemente "musical", es decir que contiene agrupaciones actualizadas ${ }^{1}$ de sonidos. ¿Se pueden encontrar algunos principios, algunas relaciones con el esquema métrico del pocma? La teoría de la instrumentación fónica fue desarrollada por los versólogos eslavos y me serviré de sus resultados. ${ }^{2}$ Bajo este término nuestros teóricos del verso comprenden el grado más alto de la organización eufónica del texto, sólo en cuanto ésta aparece de modo sistemático, se integra de algún modo en el esquema métrico y - sosteniéndose en él- lo sostiene. Así sucede con Asturias. De esta manera se da origen al verdadero tejido poético, que entrelaza y confronta palabras más distintas y distantes, produciendo tensión y juegos semánticos y acústicos. Nuestros ejemplos los sacamos del poema "Marimba tocada por indios". Al leer el verso

\section{y el chisporroteo de chorchas de fuego}

es evidente su carácter casi onomatopéyico (repetición de los fonemas $\hat{\mathbf{c}}$ y R). Pero ¿basta para explicar toda su emotividad fónica? El segundo hemistiquio," como si fuera un eco del primero. Escuchémoslo una vez más y marquemos debajo los fonemas que se repiten:

$$
\begin{aligned}
\text { y el chisporroteo } & / / \text { de chorchas de fuego } \\
\text { e } \hat{c} \text {-s-or - eo } & / / \text { e cor - s e e }
\end{aligned}
$$

Eso es una casi inalterada sucesión de una serie de fonemas. La organización eufónica de los sonidos en el verso está, a la vez, vinculada es-

1 Empleamos este término en el sentido que le dio el Círculo Linguístico de Praga, o sea: "On entend par actualisation tel emploi des moyens de la langue quel attire lui-même l'attention et qui est reçu comme quelque chose d'inusité, dépourvu d'automatisation, désautomatisé (...)" Véase Dictionnaive de linguistique de l'école de Prague, por Josef Vachek, ed. Spectrum, Utrecht/ Amberes, 1960, p. 16.

Actualización se realiza aquí tanto por la agrupación (combinación) de los sonidos en cuanto a su timbre y tonalidad como por su repetición en las partes en que se divide un verso.

a Véase Jan Mukarŏvsky: Mácháu Maj. Estetická studie. (El Mayo de Mácha. Estudio estético. Praga, 1928). Josef Hrabák: Úvod do teorje verše. (Introducción a la teoría del verso. Praga, 1958.)

3 Las cesuras se indican por $/ /$, los pies o grupos de intensidad por /. Los fonemas y sanidos según E. Alarcos Llorach: Fonología española, $4^{\mathrm{a}}$ ed.ción. Ma. drid, 1965. 
trechamente con su división en hemistiquios; sostiene el carácter íntegro y autónomo de cada uno de ellos y los confronta uno con el otro; dentro de tal marco ejerce varias funciones:

¡Serpiente que muda $/ /$ de piel en los ecos!

e-pien-e $\quad / /$ e pie en

La cufonía de nuevo sostiene la formación de los hemistiquios, y con el'o, también, la entonación bipartita del verso; en contradicción tanto con la división sintáctica del mismo como con la entonación pertinente (las pausas caerían después de serpiente y piel). Las agrupaciones actualizadas no vienen siempre en orden sucesivo.

$$
\begin{gathered}
\text { Tempestad de trinos } / / \text { entre sus costillas } \\
\text { esta } / \text { trin } / / \text { entr } / \text { sti - a }
\end{gathered}
$$

El cuadro es de un paralelismo inverso.

$$
\begin{array}{ccc}
\text { y el vuelo redondo } & / / & \text { del cielo azulejo } \\
\text { uelo/ e-o } & / / & \text { elo/ ule-o }
\end{array}
$$

En los grupos de intensidad sucesivos observamos una asimilación progresiva con el "motivo" (uelo) del primero.

$\mathrm{Y}$ ahora analicemos algunos grupos de versos:

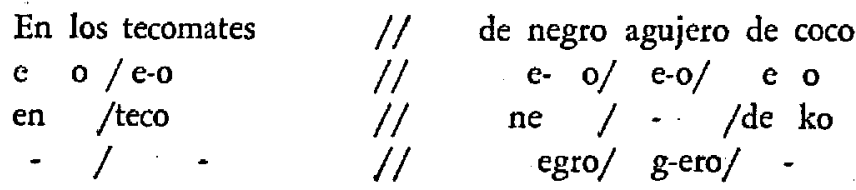

El primer verso ofrece un cuadro un poco más complicado: la agrupación actualizada principal es /e-o/, de la cual "cuelgan" las demás. La eufonía contribuye, en este caso, a la unidad del verso, expresada por la ondulación suave, y casi no interrumpida por la cesura, de su entonación. Con este rasgo contrasta bruscamente el verso siguiente:

cubiertos de tela de tripa // hay llanto de moscas

$$
\begin{aligned}
\text { b-ert } / & =\operatorname{trip} / / \text { ai } \\
\text { e-t } & / \text { a }
\end{aligned}
$$


El timbre de las vocales acentuadas separa bruscamente los hemistiquios. Crco que el contraste se acentúa aún porque el primer hemistiquio con. tinúa en la "tonalidad" del primer verso y la agudiza (e-a reducida a $e-i)$; se origina la expectación de que se vaya a continuar del mismo modo (el impulso tonal), pero ella es bruscamente frustrada. Igualmente, en el tercer verso, la eufonía se hace cargo de la confrontación de los dos hemistiquios:

$$
\begin{array}{rrr}
\text { peces-moscas } & / / & \text { y pájaros-moscas } \\
\text { e-e moskas } & / / & \text { a-a moskas }
\end{array}
$$

A la vez, "el segundo hemistiquio forma un eco vocálico casi perfecto del segundo hemistiquio del verso anterior /i a-a-o o-a/. La eufonia, pues, no se orienta sólo hacia adentro de un verso. He aquí otro grupo:

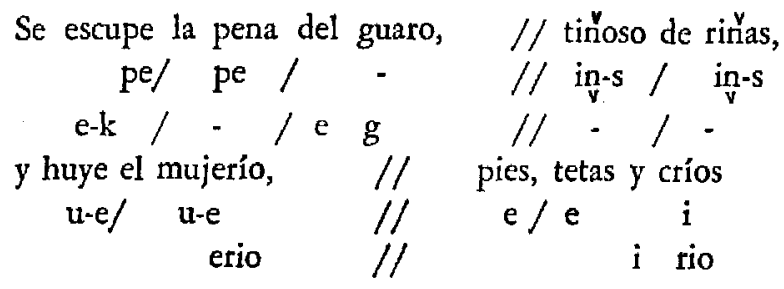

Gracias a su semejanza, las agrupaciones actualizadas del segundo verso no logran distinguir los dos hemistiquios claramente; para realizarlo, el autor se vale de rima interna (-erío). Sin embargo, cuando las dos palabras confrontadas aquí por la rima caen luego entre dos versos distintos:

Caen los refajos. Huyen ias mujeres.

Pies, tetas y críos. Plomazos. Caballos.

el autor procede a su disimilación morfológica: mujerio $>$ mujeres, sacrificando la forma más emocional, porque de otro modo se perdería la relación con los hemistiquios pertinentes al mismo verso y se rompería la estructura de verso.

En esta breve exposición me he limitado a plantear el problema de la organización cufónica del material fonemático en los versos de Asturias y a algunas sugerencias sobre el camino hacia su estudio funcional. Es una problemática tan atractiva que, según mi opinión, merecería la debida atención de los investigadores. $Y$ volvamos a Asturias en Checoslovaquia. 
Después de un año de la publicación de la antología poética, el brote de Svetová literatura tomó estatura de todo un libro. En la traducción de Zdenek Hampl y Marcela Svobodová se editó WVek-end en Guatemala (ed. de la Literatura Política, Praga, 1962). La versión chèca mantiene todas las cualidades del atte narrativo de su autor, quien, gracias a tal mediación, mereció palabras de sincero elogio de parte del eminente crítico eslovaco Alexander Matuška (1962). Traducción excelente de una obra que se estima generalmente poco. Se le echa en cara que fue escrita con fines puramente políticos, o sea limitados en tema, tiempo y espacio, etc. Sin embargo, la experiencia trágica de mi patria, en agosto de 1968, me hace sentir la necesidad de una revaloración, por lo menos de algunos de sus aspectos. El cuadro artístico que compone Asturias, de un pequeño país abatido por una Gran Potencia, lleva muchas facetas de latente alcance universal, casi típicas de nuestra época. El abuso de grandes y sagradas ideas de la humanidad para pisotear pérfidamente la libertad y soberanía de pequeños países. Condensada imagen hiperbólica que revela la escncia de la falsa propaganda que se esfuerza por justificar lo injustificable ante la opinión pública con argumentos de la "esfera de interés" correspondiente (las supuestas armas, la "propaganda por los muertos" y distintos y siempre iguales Libros Blancos, durante cuya lectura - como se dijo- uno se pone rojo, azul, verde y de un color que no integra la gama castellana...). Los "Harkins" - los ¿por qué? y la contienda entre ser instrumento y conciencia, ahogada en alcohol... Pero ¿por qué seguir vadeando el marasmo de la vida "civilizada"? La vigorosa acusación de Asturias queda en pie, capaz de resucitar dondequiera que ocurra acto de semejante barbaridad, sea su patria, Santo Domingo o Checoeslovaquia.

Un poco después de este ciclo del acercamiento a la obra del poeta y escritor guatemalteco, fue en Eslovaquia donde se dio el nucvo salto. En una de las revistas eslovacas más importantes Slovenské pabl'ady (Vistas eslovacas) apareció, en 1966 (No 11, pp. 105-11) la traducción de Leyenda del Volcán y Leyenda de la Tatuana. Aunque la versión eslovaca revela la inexperiencia de la traductora Tania Kotuliaková, fue muy importante porque contribuyó a ampliar la visión del arte de Asturias, que hasta entonces era bastante unilateral. $\mathrm{Y}$ pronto se agregó a las traducciones eslovacas El Papa Verde (ed. Slovensky spisovatel', Bratislava, 1967).

La concesión del Premio Nóbel a Asturias, al dar amplia publicidad a su obra, estimuló radicalmente este segundo ciclo, décisivo para su instalación entre los lectores de Checoeslovaquia. En Bohemia ya se pre- 
para la siembra más importante: El Señor Presidente y Hombres de maiz (ed. Svoboda, Praga). En cuanto a los homenajes, se destacaron las revistas eslovacas: Slovenské pobl'ady (1967, No 12, pp. 78-81) trajo Leyenda del Tesoro del Lugar Florido y en Revue svetovej literatury (Revista de la Literatura Mundial, 1968, No 2, pp. 160-1) apareció, adaptado, el articulo de A. Coleman: ¿Por qué Asturias? (de The New York Times Book Review). Por otra parte, en el seminario checo de cultura y política Literárni listy (Hojas literarias, 1968, No 15, p. 11) se publicó una interesantísima entrevista hecha a Asturias por Ivana Val. dés. En ella Asturias aborda muchos problemas claves de su obra (el surrealismo, el proceso creativo, el valor de la palabra en su arte, la mitologia maya, la situación económica y política de Centroamérica, etc.). $Y$ para finalizar la enumeración de los homenajes más importantes a Asturias, en el Calendario Cultural (ed. Orbis, Praga, 1969), Eduard Hodoušek, del Instituto de Lenguas y Literaturas de Praga, publica lo que se podria caracterizar como el primer ensayo checoeslovaco que se propone evaluat, en su totalidad, tanto la personalidad como la obra del escritor guatemalteco, y que excede los límites de meros apuntes.

Estamos en Checoeslovaquia, en muchos sentidos, en los umbrales del cosmos real y mágico de Asturias, porque sus mejores obras quedan por difundirse. De la siembra debemos esperar la cosecha; antes, todo intento de conclusiones sería prematuro. Lo que sí se puede decir es que la tierra es fértil y está preparada.

Instituto de Lenguas Literarias

EMIL VOLEK

Praga, Checoslovaquia 